\title{
Pengaruh E-Service Quality dan E-Trust terhadap E-Satisfaction Pada Nasabah Pengguna Aplikasi Mobile Banking Bank Tabungan Negara Bangkalan
}

\author{
Andika Mubarok ${ }^{1}$, Nirma Kurriwati ${ }^{2^{*}}$ \\ 1,2 Program Studi Manajemen Fakultas Ekonomi dan Bisnis Universitas Trunojoyo
} Madura

\section{INFO ARTIKEL}

Sejarah Artikel:

Diterima: 21 januari 2021

Diperbaiki: 6 Februari 2021

Disetujui: 14 Februari 2021

Keywords:

E-Service Quality; E-Trust; ESatisfaction.

\begin{abstract}
The purpose of this study was to determine whether there is an effect between e-servqual on e-satisfaction, to find out whether there is an effect between e-trust on e-satisfaction, and to find out whether e-servqual and e-trust have a joint influence on e-satisfaction on customers who use the $M$ Banking BTN. This study uses quantitative methods, the sampling method used is non-probability sampling. The type of data used is primary data, the data source comes from a questionnaire with a sample size of 100 respondents. The data analysis method used is multiple linear regression analysis using validity test, reliability test, normality test, multicollinearity test, heteroscedasticity test, autocorrelation test, $T$ test and $F$ test. (1) e-servqual has a positive and significantly on e-satisfaction, (2) e-trust has a positive and significant effect on e-satisfaction, (3) e-servqual and e-trust have a positive and significant effect simultaneously on esatisfaction on customer application users $m$-banking BTN.
\end{abstract}

$\triangle$ Penulis Korespondensi* Nirma Kurriwati

P-ISSN: 2775-3093

E-ISSN:

Email:

nirma.kurriwati@trunojoyo.ac.id
DOI

'Citation : Mubarok, Andika \& Nirma Kurriwati (2021), Bauran Promosi Pada Dealer Yamaha Tretan Motor Dengan Pendekatan Mixed Methods. Jurnal Kajian Ilmu Manajemen, 1 (1), hlm. 9197

\section{PENDAHULUAN}

Seiring perkembangan zaman, pertumbuhan teknologi yang cepat dan penggunaan internet yang luas dalam praktik pemasaran perusahaan semakin meningkat, maka dari itu layanan pengiriman barang ataupun jasa saat ini menggunakan program elektronik agar dapat memudahkan pelanggan dalam hal jual beli barang maupun jasa layanan melalui aplikasi elektronik. Salah satu fungsi bank yang dapat mempermudah nasabahnya yaitu menggunakan aplikasi Mobile Banking (M-Banking), pengertian Mobile Banking menurut Al-Jabri \& Sohail (2012), Mobile Banking / Perbankan seluler dapat diakses melalui telpon seluler dan transaksi menggunakan rekening pribadi, serta dapat melakukan pembayaran dan tagihan dan juga dapat mentransfer uang.

Dari hasil kapitalisasi pasar perbankan terbesar dibursa efek Indonesia pada tahun 2017, Bank BTN menduduki peringkat keenam dari 10 Bank di Indonesia yang tercatat dibursa efek Indonesia dengan total Rp. 37,1 Triliun. Maka hasil data tersebut 
menunjukkan bahwa masih kurangnya kapitalisasi pasar perbankan dibursa efek indonesia (BEI) pada Bank Tabungan Negara (BTN).

Kualitas layanan dapat mendorong nasabah untuk berkomitmen kepada jasa layanan aplikasi M-Banking pada PT. Bank Tabungan Negara (BTN) sehingga berdampak pada peningkatan penggunaan aplikasi M-Banking. Perusahaan yang memiliki system layanan yang unggul akan dapat memaksimalkan dan meningkatkan performa keuangan perusahaan (Gilbert et., al. 2004).

Kualitas pelayanan mempunyai dimensi pengukuran dalam online yang di sebut sebagai E-Service Quality. "E-Service Quality pada dasarnya merupakan pengembangan kualitas layanan jasa seperti yang telah di sampaikan sebelumnya dari cara tradisional menjadi layanan secara elektronik dengan menggunakan media seperti internet." (Dikutip dari Anton Tirta Komara, 2014). Adapun kepercayaan pada suatu situs online sering juga disebut E-Trust. Keyakinan tentang E-Trust termasuk keyakinan dan harapan konsumen online mengenai karakteristik terkait kepercayaan dari penjual online (Gefen et al., 2003). Sedangkan kepuasan dalam konteks E-Commerce yang sering disebut sebagai ESatisfaction di definisikan oleh Anderson dan Srinivasan (2003), sebagai kepuasan pelanggan sehubungan dengan pembelian sebelumnya yang diberikan oleh perusahaan E-Commerce. E-Satisfaction merupakan hasil dari evaluasi konsumen terhadap emosi terkait dengan terpenuhi tidaknya harapan konsumen berdasarkan pada pengalaman berbelanja secara online (Oliver (1997) dalam Anderson dan Srinivasan, 2003).

Selain itu perusahaan harus selalu dapat mengikuti perkembangan zaman di era teknologi ini dengan cara terus menerus untuk meningkatkan kualitas layanan elektronik (E-Service Quality) serta dapat membangun kepercayaan elektronik (E-Trust) dan akan memberikan kepuasan pelayanan elektronik (E-Satisfaction) pada pelanggan atau nasabah, serta secara tidak langsung pelanggan atau nasabah akan selalu menggunakan layanan elektronik Mobile Banking tersebut jika sistem pelayanannya baik dan memuaskan.

Permasalahan yang muncul ada 3 yaitu, 1.) Apakah E-Service Quality berpengaruh signifikan terhadap E-Satisfaction pada nasabah pengguna aplikasi Mobile Banking BTN Bangkalan ? 2.) Apakah E-Trust berpengaruh signifikan terhadap ESatisfaction pada nasabah pengguna aplikasi Mobile Banking BTN Bangkalan ? 3.) Apakah variabel E-Service Quality dan E-Trust berpengaruh secara bersama-sama terhadap E-Satisfaction pada nasabah pengguna aplikasi Mobile Banking BTN Bangkalan ?

\section{METODE PENELITIAN}

Jenis penelitian ini menggunakan pendekatan dengan metode kuantitatif yang dapat diartikan sebagai metode untuk populasi dan sampel tertentu, analisis berupa statistik dengan tujuan untuk menguji hipotesis yang telah ditetapkan, Sugiyono (2012:8).

Teknik pengumpulan data yang digunakan yaitu berupa data primer yang di peroleh dari hasil penyebaran kuesioner ke responden yang berisi pertanyaan atau pernyataan tertulis.

Metode analisis yang digunakan dalam penelitian ini adalah analisis regresi linier berganda. Teknik analisis data dalam penelitian ini menggunakan uji validitas, uji reliabilitas, uji normalitas, uji multikolinieritas, uji heteroskedastisitas, uji autokorelasi, uji T (parsial) dan uji $F$ (simultan). Serta penelitian ini menggunakan analisis deskriptif yaitu penelitian yang bersifat deskriptif artinya data yang dikumpulkan umumnya berbentuk kata, gambar dan angka. Penelitian ini menggunakan teknik Tingkat Pencapaian Responden (TCR) untuk menganalisis data yang sudah terkumpul. Tingkat Capaian Responden (TCR) yaitu suatu metode penilaian dengan cara menyusun orang yang dinilai berdasarkan peringkatnya pada berbagai sifat yang dinilai.

Adapun formulasi rumus yang dikembangkan oleh Sugiyono (2010:74), sebagai berikut:

$\mathrm{TCR}=\frac{\text { skor rata }- \text { rata }}{\text { skor maksimun }} \times 100 \%$ 
Untuk menghitung jumlah besarnya nilai rata-rata dihitung dengan rumus:

Skor rata-rata $=\frac{5 S S+4 S+3 C+2 K S+1 S T S}{n}$

Untuk menggambarkan suatu master scale dari berbagai sifat tersebut dapat dilihat pada tabel berikut ini:

\begin{tabular}{|c|c|}
\hline Kriteria & $\begin{array}{c}\text { Tingkat Capain Responden } \\
\text { (\%) }\end{array}$ \\
\hline Sangat Baik & $90-100$ \\
\hline Baik & $80-89$ \\
\hline Cukup Baik & $70-79$ \\
\hline Kurang Baik & $55-69$ \\
\hline Tidak Baik & $1-54$ \\
\hline
\end{tabular}

Sumber: Sugiyono (2010:78)

Analisis Regresi Linier Berganda

$Y=a+b_{1} X_{1}+b_{2} X_{2}$

Dimana $\mathbf{Y}$ merupakan variabel dependen, $\mathbf{a}$ adalah bilangan konstanta, $\mathbf{b}_{\mathbf{1}}, \mathbf{b}_{\mathbf{2}}$ adalah koefisien regresi pertama dan kedua, $\mathbf{X}_{\mathbf{1}}$ adalah variabel independen pertama, $\mathbf{X}_{\mathbf{2}}$ adalah variabel independen kedua.

HASIL

Analisis Regresi Linier Berganda

Tabel 2. Hasil Analisis Regresi Linier Berganda

\begin{tabular}{ccc}
\hline $\begin{array}{c}\text { Variabel } \\
\text { Independen }\end{array}$ & \multicolumn{2}{c}{$\begin{array}{c}\text { Unstandardized } \\
\text { Coefficients }\end{array}$} \\
\cline { 2 - 3 } & $\mathbf{B}$ & Std. Error \\
\hline (Constant) &, 509 & 1,054 \\
\hline TOTAL_X1 &, 504 &, 027 \\
\hline TOTAL_X2 &, 097 &, 049 \\
\hline
\end{tabular}

Sumber: Data primer diolah (2020)

Berdasarkan tabel diatas, maka persamaan analisis regresi linier berganda yang terbentuk adalah sebagai berikut:

$Y=0,509+0,504 X 1+0,097 X 2$ berikut:

Berdasarkan hasil persamaan regresi diatas, maka dapat dijelaskan sebagai

1. Nilai konstanta menunjukkan nilai sebesar 0,509 , maka hasil menunjukkan bahwa jika nilai variabel bebas yang terdiri dari E-Service Quality dan E-Trust bernilai 0, maka variabel terikatnya yaitu $\mathrm{E}$-Satisfaction pada nasabah pengguna aplikasi Mobile Banking BTN akan tetap meningkat sebesar 0,509.

2. Jika variabel E-Service Quality mengalami kenaikan dengan catatan variabel bebas yang lainnya bernilai konstan, maka E-Satisfaction pada nasabah pengguna aplikasi Mobile Banking BTN akan mengalami peningkatan sebesar 0,504. 
3. Jika variabel E-Trust mengalami kenaikan dengan catatan variabel bebas yang lainnya bernilai konstan, maka E-Satisfaction pada nasabah pengguna aplikasi Mobile Banking BTN akan mengalami peningkatan sebesar 0,097.

Tabel 3. Uji T (Parsial)

\begin{tabular}{ccc}
\hline Variabel & $\mathbf{T}$ & Sig. \\
\hline $\mathbf{X} 1$ & 18,992 &, 000 \\
\hline $\mathbf{X} 2$ & 1,992 &, 049 \\
\hline \multicolumn{3}{l}{ Sumber: } \\
Data & primer diolah $(2020)$
\end{tabular}

Berdasarkan tabel diatas, maka dapat dijelaskan masing-masing variabel independennya sebagai berikut:

1.E-Service Quality (X1)

Berdasarkan hasil Uji t diperoleh nilai variabel E-Service Quality (X1) dengan t-hitung sebesar 18,992 > t-tabel 1,985 dengan tingkat signifikansi sebesar $0,000<0,05$. Maka dapat disimpulkan bahwa variabel E-Service Quality berpengaruh positif dan signifikan terhadap variabel dependennya yaitu E-Satisfaction pada nasabah pengguna aplikasi Mobile Banking BTN Bangkalan.

2. E-Trust (X2)

Berdasarkan hasil Uji $t$ diperoleh nilai variabel $E$-Trust (X2) dengan $t$-hitung sebesar $1,992>\mathrm{t}$-tabel 1,985 dengan tingkat signifikansi sebesar $0,049<0,05$. Maka dapat disimpulkan bahwa variabel E-Trust berpengaruh positif dan signifikan terhadap variabel dependennya yaitu E-Satisfaction pada nasabah pengguna aplikasi Mobile Banking BTN Bangkalan.

Tabel 4. Uji F (Simultan)

\begin{tabular}{|c|c|c|}
\hline Mean Square & $\mathrm{F}$ & Sig. \\
\hline \begin{tabular}{|c|}
289,478 \\
1,604
\end{tabular} & 180,420 &, $000^{\circ}$ \\
\hline
\end{tabular}

Berdasarkan pengujian pengaruh variabel bebas secara bersama-sama terhadap variabel terikat dapat dilakukan dengan menggunakan uji $F$ hasil perhitungan statistik seperti yang sudah tertera pada tabel diatas yang menunjukkan F-hitung sebesar $180,420>$ F-tabel 3,09 dengan signifikansi sebesar $0,000<0,05$. Maka dapat disimpulkan bahwa hipotesis yang mengatakan variabel independen yang terdiri dari $\mathrm{E}$ Service Quality (X1) dan E-Trust (X2) secara simultan atau bersama-sama dapat mempengaruhi variabel terikatnya E-Satisfaction $(\mathrm{Y})$ pada nasabah pengguna aplikasi Mobile Banking BTN dapat diterima dan terbukti. 


\section{PEMBAHASAN}

H1 : Berdasarkan hasil analisis regresi linier berganda pada uji t (parsial) untuk variabel E-Service Quality (X1), dapat ditemukan bahwa variabel E-Service Quality berpengaruh positif dan signifikan terhadap variabel E-Satisfaction. Pengaruh tersebut disebabkan karena rata-rata semua indikator berada dalam kategori cukup baik bahwa kualitas pelayanan melalui elektronik (E-Service Quality) cukup kuat sehingga nasabah pengguna aplikasi Mobile Banking BTN merasa cukup puas dengan pelayanan elektronik pada aplikasi Mobile Banking BTN. Hasil Uji t diperoleh dari nilai t-hitung untuk variabel EService Quality (X1) dengan t-hitung sebesar 18,992 > t-tabel 1,985 dengan tingkat signifikansi sebesar 0,000 $<0,05$. Maka hasil ini menunjukkan bahwa E-Service Quality menjadi hal yang dapat mempengaruhi nasabah dalam merasakan kualitas pelayanan elektronik yang ada dalam aplikasi Mobile Banking BTN karena dengan adanya pelayanan elektronik yang berkualitas nasabah dapat merasakan kepuasan pada layanan aplikasi Mobile Banking tersebut. Sehingga Bank BTN perlu untuk meningkatkan kualitas pelayanan elektroniknya agar senantiasa nasabah tetap merasakan kepuasan dengan layanan yang dimiliki aplikasi Mobile Banking BTN. Dengan demikian variabel EService Quality (X1) berpengaruh signifikan terhadap E-Satisfaction (Y) yang didukung dengan penelitian sebelumnya oleh Dhika Prasetya Ramadhana (2019).

H2 : Berdasarkan hasil analisis regresi linier berganda pada uji t (parsial) untuk variabel E-Trust (X2), dapat ditemukan bahwa variabel E-Trust berpengaruh positif dan signifikan terhadap variabel E-Satisfaction. Pengaruh tersebut disebabkan karena rata-rata semua indikator menyatakan kepercayaan elektronik (E-Trust) terhadap variabel kepuasan elektronik (E-Satisfaction) mempunyai pengaruh cukup baik sehingga nasabah percaya dengan keamanan pada aplikasi Mobile Banking BTN yang paling utama kepercayaan pada Bank Tabungan Negara (BTN) itu sendiri. Uji t diperoleh dari nilai t-hitung untuk variabel E-Trust (X2) dengan t-hitung sebesar 1,992 > t-tabel 1,985 dengan tingkat signifikansi sebesar 0,049<0,05. Maka hasil ini menunjukkan bahwa E-Trust menjadi hal yang mempengaruhi nasabah dalam merasakan kepercayaan elektronik pada aplikasi Mobile Banking BTN karena apabila nasabah sudah percaya dengan aplikasi Mobile Banking BTN yang digunakan secara tidak langsung nasabah akan merasakan kepuasan layanan elektronik pada penggunaan aplikasi Mobile Banking tersebut. Dengan demikian variabel $\mathrm{E}$-Trust $(\mathrm{X} 2)$ berpengaruh signifikan terhadap $\mathrm{E}$-Satisfaction $(\mathrm{Y})$ yang didukung dengan penelitian sebelumnya yang diteliti oleh Aisyah Fitriani (2018).

H3 : Berdasarkan hasil Uji F (simultan) pada analisis regresi linier berganda dapat diketahui bahwa hipotesis yang menyatakan bahwa semua variabel independen yang terdiri dari E-Service Quality (X1) dan E-Trust (X2) berpengaruh positif dan signifikan secara bersama-sama (simultan) terhadap variabel dependen yaitu E-Satisfaction (Y) pada pengguna aplikasi Mobile Banking BTN. Sehingga hipotesis tersebut mempunyai nilai F-hitung sebesar 180,420 > F-tabel 3,09 dengan tingkat signifikansi sebesar 0,000< 0,05 . Dengan demikian maka dapat disimpulkan bahwa hipotesis yang menyatakan variabel independen yang terdiri dari E-Service Quality (X1) dan E-Trust (X2) secara simultan atau bersama-sama dapat mempengaruhi variabel terikatnya E-Satisfaction $(\mathrm{Y})$ maka dapat diterima dan terbukti. Dengan demikian penelitian ini didukung oleh penelitian sebelumnya yang diteliti oleh Catur Kurniawan (2018). 


\section{Tabel 5 Karakteristik Responden Berdasarkan Jenis Kelamin}

\begin{tabular}{lccc}
\hline No & Jenis Kelamin & Jumlah & Persentase \\
\hline 1. & Laki-laki & 48 & $48 \%$ \\
\hline 2. & Perempuan & 52 & $52 \%$ \\
\hline & Jumlah & 100 & $100 \%$ \\
\hline
\end{tabular}

Sumber: Data primer diolah (2020)

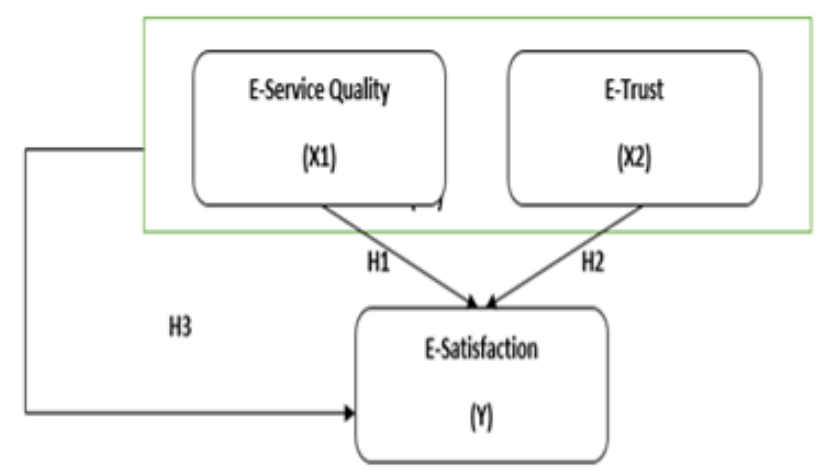

Gambar 1 Kerangka Pemikiran

\section{SIMPULAN}

Berdasarkan hasil analisis regresi linier berganda yang telah dilakukan sebelumnya maka dapat disimpulkan sebagai berikut: E-Service Quality berpengaruh positif dan signifikan terhadap E-Satisfaction pada nasabah pengguna aplikasi Mobile Banking BTN Bangkalan. E-Trust berpengaruh positif dan signifikan terhadap ESatisfaction pada nasabah pengguna aplikasi Mobile Banking BTN Bangkalan. E-Service Quality dan E-Trust berpengaruh positif dan signifikan secara bersama-sama terhadap ESatisfaction pada nasabah pengguna aplikasi Mobile Banking BTN Bangkalan.

\section{DAFTAR PUSTAKA}

Anderson, R.E. and Srinivasan, S.S, 2003. E-satisfaction and e-loyalty: a contingency Framework. Psychology \& Marketing, Vol. 20, No. 2, pp. 123- 138.

Corritore, C. L., Kracher, B., \& Wiedenbeck, S. 2003. On-line trust: Concepts, evolving themes, a model. International Journal of Human Computer Studies, 58(6), 737-758.

Santos, J., 2003. E-service quality: a model of virtual service quality dimensions, Management Service Quality. Vol. 13 No. 3, pp. 233-46.

Ribbink, D., van Riel, A.C.R., Liljander, V. and Streukens, S., 2004. Comfort your online customer: quality, trust and loyalty on the internet, Managing Service Quality. Vol. 14, No. 6, pp.446-456.

Saladin, Djaslim. 2007. Manajemen Pemasaran, Bandung; Linda Karya.

Al-Jabri, I. M., \& Sohail, M. S, 2012. Mobile Banking Adoption: Application Of Diffusion Of Innovation Theory. Journal of Electronic Commerce Research, Vol.13, No.4. 
Santouridis, llias., Trivellas, Panagiotis., dan Tsimonis, Georgios., 2012. Using E-SQUAL To Measure Internet Service Quality Of E-Commerce Web Sites In Greece. Vol 4 No.1, 86-98. International Journal of Quality and Service Sciences.

Sugiyono. 2012. Metode Penelitian Kuantitatif Kualitatif dan R\&D. Bandung: Alfabeta.

Giovanis, Apostolos N., \& Pinelopi Athanasopoulou., 2014. Gaining Customer Loyalty in the E - Tailing Marketplace : The Role of E - Service Quality, E-Satisfaction and E Trust. Int. J. Technology Marketing.Volume 9, No. 3.

Tirta Komara, Anton, 2014. Keterkaitan E-Service Quality dan E-Recovery Service Quality Maskapai Penerbangan Air Asia dengan Menggunakan Structural Equation Modelling. Jurnal Computech \& Bisnis,Vol.8,No. 2,: 101-111.

Tjiptono, Fandy, 2014. Pemasaran Jasa (Prinsip, Penerapan, Penelitian). Yogyakarta. Andi.

Ghozali, Imam. 2016. Aplikasi Analisis Multivariete Dengan Program IBM SPSS 23 (Edisi 8). Cetakan ke VIII. Semarang: Badan Penerbit Universitas Diponegoro.

Kotler, Philip and Kevin Lane Keller, 2016. Marketing Managemen, 15th Edition, Pearson Education, Inc.

Prasetya, M. A. 2016. Pengaruh E-Service Quality Dan Trust Pada Internet Banking Terhadap Kepuasan Nasabah. SKRIPSI.

Prisanti, Mega D., Suyadi, Imam dan Arifin, Zainul. 2016. Pengaruh E-Service quality dan E-Trus Terhadap E-Customer Satisfaction Serta Implikasinya Terhadap E-customer Loyalty (Studi Pada Nasabah PT Bank Rakyat Indonesia (Persero) Tbk Kantor Cabang Pembantu Lawang). Journal of Business Studies.

Fitriani, Aisyah. 2018. Pengaruh E-Trust dan E-Service Quality Terhadap E-Loyalty Dengan E-Satisfaction Sebagai Variabel Intervening (Studi Pada Pengguna E-Commerce C2C Shopee).

Kurniawan, C., 2018. Pengaruh E-Service Quality, E-Trust Dan E-Satisfaction Terhadap E-Loyalty Konsumen Muslim Pada MarketPlace Tokopedia Dan Bukalapak. Tulungagung: 22 juli 2019.

Ramadhana, Dhika Prasetya, 2019. Pengaruh E-Service Quality Dan E-Trust Terhadap E-Loyalty Dengan E-Satisfaction Sebagai Variabel Intervening (Studi pada Pengguna ECommerce Shopee). S1 thesis, Fakultas Ekonomi, Univer-sitas Negeri Yogyakarta.

Ayu Mas Suariedewi, N. W., I Gusti Agung, 2020. Effect of Mobile Senvice Quality to ETrust to Develop E-Satisfaction and E-Loyalty Mobile Banking Services. International Research Journal of Management, IT \& Social Sciences, 7 No.1 January 2020, 185-196.

Nawangsari, Sri dan Nadea Dwirahma Putri. 2020. Pengaruh E-Service Quality dan ETrust Terhadap Kepuasan Nasabah Pengguna BNI Mobile Banking Melalui Citra Bank Sebagai Variabel Intervening (Studi Kasus Pada Nasabah Pengguna BNI Mobile Banking di Kota Depok), Fakultas Ekonomi, Universitas Gunadarma. 